\title{
MEDICAL PROFILE OF PATIENTS ATTENDING DENTAL PRIMARY CARE CLINICS IN KING SAUD UNIVERSITY, SAUDI ARABIA: A RETROSPECTIVE STUDY
}

\author{
Ola Abdullah Alshuhail*, Aryaf Albajadley**, Bashaer Almousa**, \\ Dalal Albadrani**, Eman Bin Saleh** and Sarah Aljebreen ${ }^{* *}$
}

\begin{abstract}
Background: Advancement of health care was salient which resulted in more people living longer with complex medical conditions seeking dental care.

Objective: To assess the medical profile of patients attending primary dental care clinics in the College of Dentistry, King Saud University, Riyadh, Saudi Arabia.

Methods medical records of 312 adult female patients who presented to primary care clinic and filled the standardized medical questionnaire in the period from $9^{\text {th }}$ of July to $9^{\text {th }}$ of August 2017 were randomly selected and reviewed. Collection of data was done which included demographic data, chief complaint, medications, and current medical condition
\end{abstract}

Results: The age group ranged from 18 to 77 years old, (28\%) of patients have at least one medical condition, and $22.44 \%$ of patients are taking medications. The most common medical condition was anemia (11.9\%) followed by short of breath $(6.1 \%)$, chest pain and diabetes mellitus (DM) $(5.4 \%)$, hepatitis (3.8\%), ankle swelling (3.5\%), bleeding disorder (2.6\%), asthma and arthritis $(2.2 \%)$, heart trouble $(1.0 \%)$, Rheumatic arthritis, Kidney trouble, Hepatitis and Cancer $(0.3 \%)$. Age category (forty-six to fifty-five years old) had the highest rate of medical problems $75 \%$

Conclusion: Results showed that approximately one-quarter of patients attending the primary dental clinics have a medical problem. It is important that dental practitioners be knowledgeable about the proper management of patients with medical problems. Further studies are recommended to extend the study period.

KEYWORDS: Dental clinic; medical history; systemic diseases; medical conditions.

\footnotetext{
* Oral Medicine, Orofacial Pain, Dental Sleep Medicine College of Dentistry, King Saud University.

** Dental Student College of Dentistry King Saud University.
} 


\section{INTRODUCTION}

In the $21^{\text {st }}$ century, the medical field witnessed a magnificent advancement ${ }^{1}$, a significant elevation in the world population numbers was inevitable, which lead to an increased lifespan. ${ }^{2}$ Thus, the numbers of older medically compromised patients seeking dental treatment and in need of special consideration is likely to grow larger. ${ }^{3}$

Improvements in oral health care were also notable which resulted in more patients preserving their natural teeth for a longer time when compared to previous generations. Thus, it is unavoidable that dentists will face a large number of patients who are suffering from medical conditions presenting with dental problems. ${ }^{4}$ Previous studies have shown that half of all patients treated in dental schools suffer from at least one chronic disease. ${ }^{5}$

It has been noted that there is a correlation between systemic health and oral condition. Patients suffering from medical conditions can compromise their tolerance for dental treatment and the ability to maintain proper oral hygiene. ${ }^{8}$ Moreover, the oral condition reflects general health for the treating dentist to notice and to be aware of any signs that may affect the dental treatment..$^{9-11}$ Therefore, dental treatment provided by dental health care professionals should be adjusted accordingly for each individual patient presenting with medical conditions if required. Which emphasize the importance of evaluating and reviewing the full medical history of each patient before dental treatment. ${ }^{12}$

Primary care in dentistry is the first encounter with the patients seeking emergency dental treatment who may present with medical condition whether they are aware of it or not. ${ }^{15}$ Dentists in primary care clinics take major rule in acknowledging and recognizing oral manifestations of diagnosed and undiagnosed medical conditions. ${ }^{16,17}$
Facing medical emergency situations might be infrequent in daily dental routine practice, however, in the event of occurrence, it could be life-threatening. ${ }^{18}$ Therefore, the individual dental health professional must be familiar and trained appropriately to assess the level of invasiveness of the procedure and modify the dental treatment according to their patients' conditions. ${ }^{19}$

The literature showed the most common medical emergencies were most likely to occur during the delivery of local anesthesia, extraction and endodontic treatment all of which takes place in the dental primary care clinic. ${ }^{21}$ Unfortunately, many dental clinics including primary care cannot receive medically compromised patients due to lack of preparedness and equipment. ${ }^{22}$

Annual education courses and office medical emergency drills ensure a rapid response to emergency situations. The combination of knowledgeable and skilled dental health professionals with the equipment for basic airway rescue and oxygenation, monitoring equipment, and a basic drug emergency kit that makes the dental office a safer environment for patients and enhances dental professionals' capability to render competent and timely aid. ${ }^{22}$

Awareness of the most common medical conditions will facilitate in preparing and handling medical emergencies that might occur in the dental clinic. In spite of that, there is a lack of evidence regarding the prevalence of medical conditions among patients seeking dental care in Saudi Arabia, Riyadh.

The aim of this study was to assess the medical profile of patients attending the primary care clinic in the College of Dentistry at King Saud University during the period from $9^{\text {th }}$ July 2017 until $9^{\text {th }}$ August 2017. 


\section{MATERIALS AND METHODS}

\section{Target population}

This study is a retrospective cross-sectional chart review. It is approved by the College of Dentistry Research Center (CDRC), at King Saud University, Saudi Arabia.

Patients' records were randomly selected from among patients seeking dental treatment at the primary dental clinic in the College of Dentistry, King Saud University, Riyadh, Kingdom of Saudi Arabia, between the period of $9^{\text {th }}$ of July and $9^{\text {th }}$ of August 2017.

Objectives of primary dental center in a teaching dental college:

- The primary care clinic is a service provided by the College of Dentistry at King Saud University for comprehensive examination, treatment and is consider as a corner stone of patient's acceptance.

- The newly graduate dentist is required to undertake a twelve-month internship as a fundamental requirement for full registration as a dental practitioner by the Saudi Commission for Health Specialties so the primary clinics will be operated by them to improve their knowledge, skills and attitude in the practice of general dentistry, to gain more experience in risk assessment, and management of medically compromised cases as well as emergency and primary dental care, to introduce the actual dental practice including the different styles of practicing dentistry by exposing Intern to different working environments and clinic set-ups.

- Through the primary care clinic and after examination of the patient, the appropriate and suitable cases are referred to the undergraduate students to be used in required courses.

A total of 312 patients' records were included in the study for chart review. Patients included in this study were all female; because the nature of the College of Dentistry at King Saud University is for women and children only, eighteen years old and older who had completed the standardized medical questionnaire (patient's record/file). The patients' charts were reviewed for demographic data, dental chief complaint, medical conditions, allergy, smoking.

\section{Chart Review}

Every patient's record/file included in the study was thoroughly reviewed by a minimum of two examiners. Demographic da ta included from patients' charts were (age, gender, marital status, nationality, and occupation). Collected data regarding dental chief complaint were categorized as pain $\backslash$ toothache, infection $\backslash$ abscess, bleeding, swelling $\backslash$ inflammation, broken restoration $\backslash$ tooth, others and not written. Medical conditions were categorized systemically and medications were categorized based on their therapeutic usage. Systemic conditions were coded as Rheumatic fever, Heart trouble, Epilepsy, Tuberculosis, Kidney trouble, Aids, Hypertension, Diabetes mellitus, Jaundice, Hepatitis, Cancer, Arthritis, Venereal disease, Bleeding disorder, Anemia, Short of breath, Chest pain, Ankle swelling, Asthma, Others, Allergy (Food $\backslash$ substance, Penicillin, Other medication). Used medication was coded as yes, no and name of the medication. Other collected data were coded regarding cortisone treatment (Yes, No), smoking (cigarette \shisha, SnifflChew tobacco).

\section{Statistical Analysis}

The data were coded and entered into a Microsoft Excel spreadsheet and analyzed using the SPSS version 17.0 statistical package (SPSS, Chicago, IL, USA).

Descriptive statistics (percentage, frequency, and means) were calculated to obtain the prevalence of medical conditions among dental patients attending dental primary care clinics. 


\section{RESULTS}

A total of 516 patients came for primary care clinic between 9th of July and 9th of August 2017, 312 patients were included in this study. The sample age range was eighteen to seventy-seven years; their mean age was $35.82,(100 \%)$ were female as the study was conducted in all-female campus, as for the marital status $127(40.7 \%)$ of the patients were single, 168 (53.8\%) were married and 17 (5.4\%) did not specify. The nationality distribution revealed $270(86.5 \%)$ patients were Saudi and $42(13.5 \%)$ were non-Saudi. As for the occupation, 109 (34.9\%) were employees while 89 (28.5\%) were non-employee, $63(20.2 \%)$ were students and 51 (16.3\%) did not specify.

Table 1, shows the distribution of the dental chief complaint with almost half of the patients 133 (42.6\%) not filling in the chief complaint question, and $110(35.3 \%)$ came for a checkup and dental treatment.

The total of patients with compromising medical conditions were $87(27.88 \%)$ having at least one medical conditions, with 225 patients $(72.12 \%)$ did not report any medical conditions as shown in figure 1.

Prevalence rate of medical conditions among the study population (Table 2), the most common medical conditions were, in decreasing frequency, Anemia (11.9\%), Short of breath (6.1\%), Chest pain and DM (5.4\%), Hepatitis (3.8\%), Ankle swelling (3.5\%), Bleeding disorder (2.6\%), Asthma and Arthritis (2.2\%), Heart trouble (1.0\%), Rheumatic arthritis, Kidney trouble, Hepatitis, Pregnancy and
TABLE (2) Prevalence of medical conditions among the study population $(\mathrm{N}=312)$

\begin{tabular}{|c|c|c|}
\hline Medical condition & Frequency & Percentage \\
\hline None & 225 & $72.11 \%$ \\
\hline Rheumatic fever & 1 & $0.3 \%$ \\
\hline Cardiac diseases & 3 & $1.0 \%$ \\
\hline Hydney diseases & 1 & $0.3 \%$ \\
\hline DM & 12 & $3.8 \%$ \\
\hline Hepatitis & 17 & $5.4 \%$ \\
\hline Cancer & 1 & $0.3 \%$ \\
\hline Arthritis & 1 & $0.3 \%$ \\
\hline Bleeding disorder & 7 & $2.2 \%$ \\
\hline Anemia & 37 & $2.6 \%$ \\
\hline Short of breath & 19 & $11.9 \%$ \\
\hline Chest pain & 17 & $6.1 \%$ \\
\hline Ankle Swelling & 11 & $5.4 \%$ \\
\hline Asthma & 7 & $3.5 \%$ \\
\hline
\end{tabular}

Cancer $(0.3 \%)$. Other medical conditions the patients reported and were not listed in the questionnaire counted as 11 (3.5\%) (Figure 2).

Pharmaceutical usage, $50(16.0 \%)$ patients were taking medications which were categorized (Figure 3), and $20(6.4 \%)$ of patients were taking cortisone and they did not specify the condition for taking it. Six (1.9\%) patients reported an allergy to Food/Substance while 4 (1.3\%) have an allergy to penicillin in addition to $3(1.0 \%)$ having an allergy to other medications and $22(7.1 \%)$ did not mention. Regarding smoking, 3 (1.0\%) of patients were sniffing/chewing tobacco and only one patient was pregnant $(0.3 \%)$.

TABLE (1) Distributions of subjects according to the dental chief complaint $(\mathrm{N}=312)$.

\begin{tabular}{|l|c|c|c|c|c|c|c|c|}
\hline $\begin{array}{l}\text { Chief } \\
\text { complaint }\end{array}$ & Pain & Infection & Swelling & $\begin{array}{c}\text { Broken } \\
\text { tooth/ restoration }\end{array}$ & $\begin{array}{c}\text { Check } \\
\text { up }\end{array}$ & $\begin{array}{c}\text { Not } \\
\text { written }\end{array}$ & Others & Total \\
\hline Frequency & 22 & 2 & 1 & 3 & 110 & 137 & 37 & 312 \\
\hline Percentage & $7.1 \%$ & $0.6 \%$ & $0.3 \%$ & $1.0 \%$ & $35.3 \%$ & $43.9 \%$ & $11.9 \%$ & $100 \%$ \\
\hline
\end{tabular}




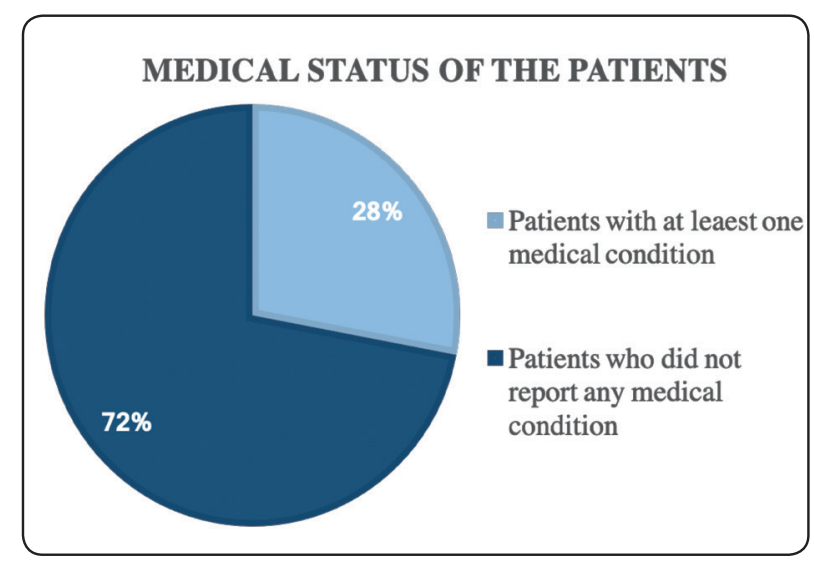

Fig. (1) Prevalence and percentage of the medical status of the subjects $(\mathrm{N}=312)$.

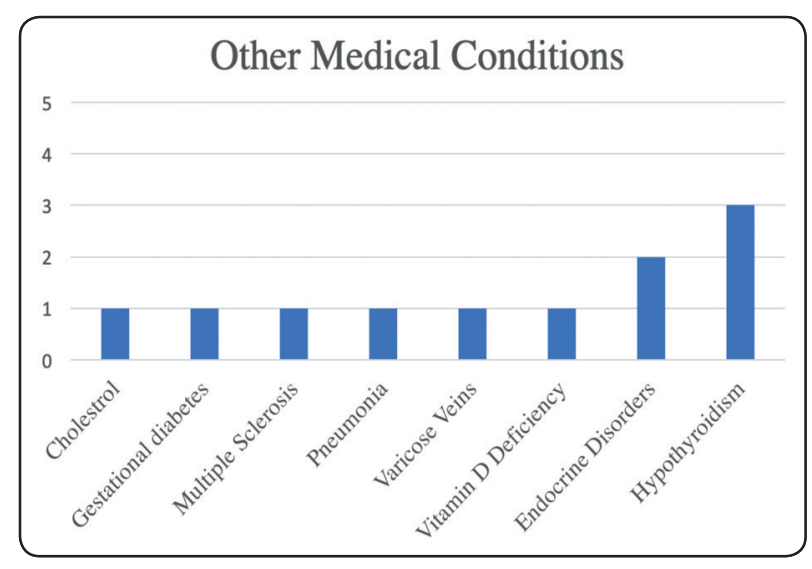

Fig. (2) Frequency of other medical conditions not listed in the standardized patient medical questionnaire.

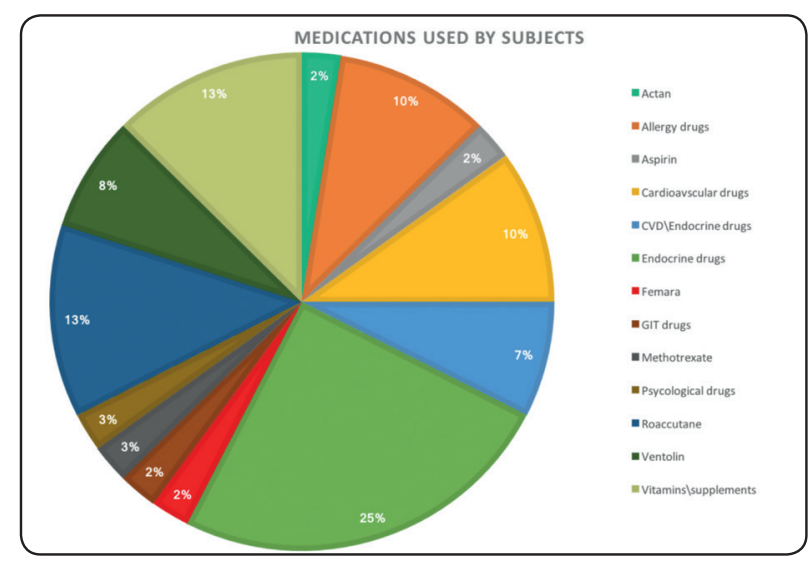

Fig. (3) Type and percentage of medications used by subjects.

\section{DISCUSSION}

In this study, we aspire to raise awareness among dentists in primary care to be able to recognize any medical emergency and how to manage $i t^{23}$, and to contribute in helping educational establishments providing proper training and extensive knowledge of the emergency protocols ${ }^{24}$, as well as equipping clinics with emergency carts to be ready for initial response to medical emergencies of the most common medical conditions ${ }^{25}$. Caution must be taken in dealing with patients who are suffering from serious medical situations to reduce the morbidity and mortality rate. ${ }^{20}$

Results of this study may help to establish the knowledge of the most common medical conditions among patients residing in the area, providing the dental interns and dentists with a baseline to improve their skills managing medical emergencies during a dental procedure and delivering efficient harmless treatment, to avoid any complication certain measures should be followed, This includes, and not limited to, taking consultation and clearance from physicians when needed, awareness of the medications that the patient is taking, and extensive knowledge of the most common medical conditions among the population that the dentist serves. Taking these precautions will ensure accurate diagnosis, prognosis and effective treatment without medical crisis. $^{13,14}$

Besides, the dentist should emphasis on the patients to share their medical history and explain its significance on the dental treatment, as some tend to neglect or hide their information, either they diminish the relatability to dentistry or out of fear that it might delay their appointment or deprive them of the free treatment that is provided by the college.

For this study the medical history of 312 patients were reviewed, the prevalence of patients suffering from at least one medical condition was $(28 \%)$ which falls under the range (10-69\%) that is reported in the literature $^{2,12,13}$, based on diverse patients' structure 
that was reviewed, the middle age group aging from the fifth to the sixth decades of age (56-65 years) had the highest rate of medical problems among the subjects which are estimated to be at $(75 \%)$.

Most of the literature and studies conducted showed cardiovascular diseases as the predominant medical condition in patients seeking dental care in general. However, in the present study, the most common medical condition was Anemia (11.9\%) followed by shortness of breath (6.1\%). In 2000, a study by Alquaiz et al. concluded that anemia rate in Saudi Arabia alone was (20.5\%) (females $>=15 \mathrm{yrs}, \mathrm{Hb}<130 \mathrm{~g} / \mathrm{L}$ males $>=15 \mathrm{yrs}$ ); This study showed significant associations between anemia and female gender ${ }^{26}$, which relate to the present study being only limited to female with a majority being of a young age (18-35 years accounting to $55 \%$ of the sample). This leads to increasing needs to emphasize the adequate knowledge of the sign, symptoms and complication that associate with anemia which includes fatigue, low physical and mental capacity, headache, vertigo, leg cramps, pagophagia, and cold intolerance, being aware of these signs and symptoms including shortness of breath which was the second common condition in this study, might help in recognizing undiagnosed anemia and request the laboratory testing ${ }^{28}$.

Al-Bayaty. et al, conducted a study regarding the medical profile in the University of the West Indies and reported their highest level of medical issues were hypertension (12.6\%) and diabetes $(6.1 \%)$ among 571 individuals ${ }^{12}$, a similar study was conducted in Saudi Arabia which concluded that $20 \%$ of the patients reported at least one medical condition, diabetes was the most common condition accounting for $(7.2 \%)$ followed by hypertension (5.4\%) and anemia (3\%) $)^{29}$. In 2004 a communitybased national epidemiological health survey by Al-Nozha et al, conducted by examining Saudi subjects in the age group of 30-70-years, 4004 subjects (23.7\%), out of 16917 were diagnosed to have Diabetes mellitus ${ }^{30}$, in this study the Diabetes mellitus reported to be $(5.4 \%)$, diabetes co-relate significantly to the oral condition as it results in periodontal disease ${ }^{31}$. The difference might be related to the age of our subjects which are younger compared to Al-Nozha study.

In regards to hypertension Radfar and Suresh conducted a study in New York, out of 1,041 patients (22\%) had hypertension which was the highest rate in their results ${ }^{2}$, in comparison with this study hypertension accounted for (3.8\%), Hypertension is increasing in prevalence in Saudi Arabia the latest survey done by the Saudi ministry of health conducted that (51\%) of Saudis aging (55-64 years) have hypertension ${ }^{32}$, screening of adults who show signs and symptoms of hypertension earlier will help reveal undiagnosed condition and avoiding serious complications in the dental set-up ${ }^{33}$.

\section{CONCLUSION}

With the advancement in medical technology and increased life expectancy, it's inevitable for the dentist to treat medically compromised patients as shown in the results more than quarter of the patients reported at least one medical condition. As well as the medication the patient is taking might interfere with the course of the dental treatment.

\section{RECOMMENDATIONS}

- Emphasizing on the importance of medical history as a mandatory part of all clinical visits.

- Primary care clinic should be well prepared to treat any patient with a medical condition by the availability of the equipment and trained staff to provide an efficient and safe dental treatment.

- We suggest conducting further studies to investigate the prevalence of medical conditions in each age group (Pediatric, adolescents, adults, Geriatric) and to involve both genders with longer study period in addition to collecting other medical conditions not listed in the standardized patient medical questionnaire. 


\section{LIMITATIONS}

This research was conducted in the college of dentistry, King Saud University, at the female campus where they only receive female patients.

\section{REFERENCES}

1. Başlarlı Ö., Adiloğlu I., Taşar F., Tümer C., Saysel M.Y. Medical profile of a dental school patient population. Clinical dentistry and research 2014; 38 28-35.

2. Radfar L., Suresh L. Medical profile of a dental school patient population. J of Dent Educ 2007; 71: 682-686.

3. Abdul Razak P,Jose Richard K.M, Thankachan R.P, Abdul Hafiz K.A, Kumar N.K, Sameer K.M. Geriatric Oral Health: A Review Article. J int oral health. 2014; 6 110116.

4. Patel N, Broadfield L.J., Mellor A.C., Medical profile of patients accessing hospital-based emergency dental care. Oral Surgery 2014; 7: 26-32.

5. Anders P.L, Comeau R.L,Hatton M, Neiders M.E, The Nature and Frequency of Medical Emergencies Among Patients in a Dental School Setting. Journal of Dent Educ 2010; 74 392-296.

6. Shay K.,Ship J.A.The Importance of Oral Health in the Older Patient. JAGS 1995; 43: 1414-1422.

7. Sheliham A, Steele J. Does the condition of the mouth and teeth affect the ability to eat certain foods, nutrient and dietary intake and nutritional status amongst older people? Public health nutrition 2001; 4 797-803.

8. Sachdeva S.K, Raj S.S, Kaushik et al. Prevalence of Medical Problems among Patients Attending a Dental School in India-A Cross Sectional Study. J of OHDM. 2015; 14 429-434.

9. Naito M., Yuasa H., Nomura Y., Nakayama T., Hamajima N., Hanada N., Oral health status and health-related quality of life: a systematic review. J of oral sci 2006; 48: 1-7.

10. Lo Russo L, Guida L, Di Masi M, Adverse drug reactions in the oral cavity. Current Pharmaceutical Design. 2012;18 5481-96.

11. Dhanuthai K., Sappayatosok K., Bijaphala P., Kulvit S., Sereerat T. Prevalence of medically compromised conditions in dental patients. Med Oral Patol Oral Cir Bucal. 2009;14 287-91.
12. Al-Bayaty H.F., Murti P.R., Naidu R.S., Matthews R., Simeon D. Medical Problems Among Dental Patients at the School of Dentistry, The University of the West Indies. J of Dent Educ 2009; 73: 1408-14.

13. Aggarwal A, Panat S.R, Talukder S. Self-Reported Medical Problems Among Dental Patients in Western Uttar Pradesh, India. J of dent educ. 2011; 75 1635-40.

14. Agarwal A, Dev N.D. Prevalence of Self-Reported Medical Conditions and Drugs Used in Periodontally Compromised Geriatric Population. J of periodontology and implant dentistry 2013; 5 66-70.

15. Gambhir R.S. Primary Care in Dentistry - An Untapped Potential. J Family Med Prim Care. 2015; 4: 13-18.

16. Giddon DB., Swann B., Donoff RB., Hertzman-Miller R. Dentist as oral physicians: the overlooked primary health care resources. J prim prev. 2013; 34 279-91.

17. Absi E.G, Satterhawaite J, Shepherd J.P, Thomas D.W.The appropriateness of referral of medically compromised dental patients to hospital. Br J Oral Maxillofac Surg. 1997; 35 133-6.

18. Josh S, Acharya. Medical Emergencies in Dental Practice - A Nepalese study. Orthodontic J of Nepal. 2015; 5 33-7.

19. Arsati F, Montalli V.Â, Flório F.M, et al. Brazilian dentists' attitudes about medical emergencies during dental treatment. J Dent Educ. 2010; 74 661-6.

20. Girdler N.M, Smith D.G. Prevalence of emergency events in British dental practice and emergency management skills of British dentists. Resuscitation.1999; 41: 159-167.

21. Hass D.A, Management of Medical Emergencies in the Dental Office: Conditions in Each Country, the Extent of Treatment by the Dentist. Anesth prog. 2006; 53: 20-24

22. Rosenberg M. Preparing for Medical Emergencies: The Essential Drugs and Equipment for the Dental Office. J Am Dent Assoc. 2010; 141: 14-19.

23. Elanchezhiyan S, Elavarasu S, Vennila K, et al. Awareness of Dental Office Medical Emergencies Among Dental Interns in Southern India: An Analytical Study. J Dent Educ. 2013; 77: 364-369.

24. Hass D.A, Preparing Dental Office Staff Members for Emergencies: Developing a Basic Action Plan. J Am Dent Assoc. 2010; 141: 8-13.

25. Dym H. Preparing the Dental Office for Medical Emergencies. Dent clin North Am. 2008; 52: 605-608. 
26. Alquaiz A.J., Khoja T.A., Alsharif A., Kazi A., Mohamed A.G., Al Mane H., Aldiris A., Shaikh S.A. Prevalence and correlates of anaemia in adolescents in Riyadh city, Kingdom of Saudi Arabia. Public Health Nutr. 2015; 18: 3192-3200.

27. Api O, Breyman C, Çetiner M, Demir C, Ecder T Diagnosis and treatment of iron deficiency anemia during pregnancy and the postpartum period: Iron deficiency anemia working group consensus report, Turk J Obstet Gynecol. 2015; 12: 173-181

28. Seymour RA. Dentistry and the medically compromised patient. Surgeon. 2003;1:207 - 14.

29. Natto ZS, Al - Zahrani MS. Periodontal bone loss and self
- reported medical conditions in a dental school patient population. J Int Acad Periodontol. 2010; 12: 104 - 9.

30. Al-Nozha MM, Al-Maatouq MA, Al-Mazrou YY, AlHarthi SS, Arafah MR, Khalil MZ. Diabetes mellitus in Saudi Arabia. Saudi Med J. 2004 Nov;25:1603-10.

31. Saini R, Saini S, Sugandha RS, Periodontal Disease: The sixth complication of diabetes mellitus, J Fam Community Med. 2011; 18: 31.

32. Survey of health information in the Kingdon of Saudi Arabia, Ministry of Health, 2013.

33. Al-Nozha MM, Abdullah M, Arafah MR. Hypertension in Saudi Arabia, Saudi Med J. 2007; 28: 77-84. 